\title{
ПОСТКОВИДНЫЙ ВАСКУЛИТ У РЕБЕНКА
}

\author{
Е.Г. Михайлова, О.В. Скворцова, И.Г. Шевкуленко, Е.В. Калабина \\ ГБУз СОДКБ им. Н.Н. Ивановой, г. Самара
}

Пациент Н., 3,5 лет находился на стационарном лечении в отделении эндокринологии СОДКБ им. Н.Н. Ивановой с 13.02.2021 по 26.03.2021. С 19.02 по 25.02 ребенок находился в ОРИТ.

13.02 мальчик с приема невролога поступил в приемный покой с жалобами на резко выраженную, прогрессирующую вялость, слабость, со слов мамы полидипсию (предпочитал сладкую воду), нарушение мочеиспускания по типу энуреза (ранее не отмечалось), позывы к рвоте, периодическое нарушение стула, ложные позывы к дефекации.

При осмотре эндокринологом в приемном покое: ребенок вялый, спит. При попытке разбудить - капризничает. Голову не держит. На коже единичные элементы петехиальной сыпи, присутствует шелушение кожи ладоней, стоп. Кожа бледная, периорбитальный цианоз. Стул кашицеобразный, без патологических примесей. Объем выпиваемой жидкости со слов мамы около 2 литров в СУтки.

ДАННЫЕ ОБСЛЕДОВАНИЯ В ПРИЕМНОМ ПОКОЕ: ГЛюКОЗа КровИ В ПределаХ НорМЫ, НезНачительный метаболический алкалоз, выраженное снижение уровней натрия (123 ммоль/л) и хлора (85 ммоль/л). Уровень калия на тот момент не определен. По УЗИ ОБП - кишечный инвагинат (рецидивирующий), устранен консервативно. Учитывая выраженные электролитные нарушения и клиническую картину, ребенок был госпитализирован в отделение эндокринологии с подозрением на надпочечниковую недостаточность.

В отделении, при поступлении повторно взяты электролиты: значительное снижение калия (3,2 ммоль/л), натрия (124 ммоль/л), хлора (86 ммоль/л), уровень кортизола в пределах нормы. Измерено АД: 160/120 мм рт.ст., пульс 150 уд/мин. Данные показатели позволили исключить надпочечниковую недостаточность. При контроле АД и пульс сохранялись на высоких цифрах, ребенку были назначены ингибиторы АПФ в возрастной дозе - без динамики. Сохранялись выраженные электролитные нарушения При постепенном увеличении дозы АГ все-равно купировалась трудно. Стабилизировать его удалось только при добавлении альфа и бетаблокаторов. 15.02 у мальчика был приступ тонических судорог, купирован в/в введением реланиума. Далее двукратно отмечались повторные эпизоды судорог. В лечении были добавлены антиконвульсанты.

Учитывая цифры АД, тахикардию, выраженные электролитные нарушения, клиническую картину - диагностический поиск был направлен на исключение вторичного гиперальдостеронизма, псевдогипоальдостеронизма, синдрома неадекватной секреции АДГ, центрального и нефрогенного сахарного диабета, параганглиомы (феохромоцитомы), интерстициального нефрита, болезни Такаясу, Кавасаки, муковисцидоза, узелкового периартериита. После проведенного обследования были выявлены отклонения: резко выраженное увеличение экскреции натрия с мочой, увеличение кальций-креатининового соотношения, увеличение KФК, положительный титр IgG к SARS CoV-2, трехкратное повышение уровней метанефрина, норметанефрина суточной мочи. По результатам МРТ головного мозга и КТ туловища с контрастированием патологических образований не выявлено. Уровни специфических и неспецифических маркеров воспаления, гормонов надпочечников, щитовидной, паращитовидной желез в пределах нормы.

В течение госпитализации и после полученных результатов мальчик был консультирован смежными специалистами: кардиологом, нефрологом, ревматологом, неврологом, гастроэнтерологм. Проведены ТМК с НМИЦ Эндокринологии. Ребенку выставлен диагноз: Основной: Постковидный васкулит, генерализованная форма с поражением сосудов кишечника, почек, периферических сосудов, тяжелой степени. Параганглиома? Осложнения: Вторичная злокачественная артериальная гипертензия 2 степени. Синусовая тахикардия.

В лечении мальчик получал: ингибиторы АПФ (112,5 мг/сут), альфа и бета-адреноблокаторы, ГКС, антиконвульсанты, инфузионную терапию с целью купирования электролитных нарушений. 


\section{СБОРНИК ТЕЗИСОВ}

XVII Российская научно-практическая конференция детских эндокринологов «Достижения науки в практику детского эндокринолога»

В течение месяца после назначенной терапии состояние ребенка с выраженной положительной динамикой. Активен, АД в пределах нормы, правда на прежней антигипертензивной терапии. Однако при повторном определении уровня метанефринов суточной мочи - сохраняется их значительной повышение. Причем уровень норметанефрина стал преобладать еще больше. Двукратно ребенок консультирован в ЭНЦ - учитывая положительную динамику в состоянии ребенка рекомендовано постепенное снижение дозы принимаемых препаратов с последующим контролем уровней метанефринов для решения вопроса о дальнейшем поиске параганглиомы.

Выписан с рекомендацией постепенного снижения дозы ГКС, осмотрен через 3 нед на фоне их отмены. Артериальное давление стабильно, активен, самочувствие не страдает, полиурии, энуреза нет. Колебания артериального давления от 105 до 115 и 65 мм рт. ст. Начато снижение антигипертензивных препаратов, приглашен на повторный осмотр через 1,5 мес. В дальнейшем планируется повторное определение уровня метанефринов. 